\title{
PROCESS-BASED MODELING OF COASTAL DUNE DEVELOPMENT
}

\author{
Martijn Muller ${ }^{1}$, Dano Roelvink ${ }^{23}$, Arjen Luijendijk ${ }^{12}$, Sierd de Vries ${ }^{1}$ \\ and Jaap van Thiel de Vries ${ }^{12}$
}

\begin{abstract}
In this paper, the aeolian transport model DUNE (Sauermann et al., 2001, Kroy et al., 2002) that describes important features and dynamics of typical desert dunes, is extended such that it can be applied in sandy coastal areas. Initial tests explore the limitations of the model in coastal areas after which adaptations are proposed and implemented. The final model version is applied to a coastal profile near Vlugtenburg (Dutch Holland coast).
\end{abstract}

Keywords: Aeolian transport; dunes; nourishments; coastal morphology; process-based modeling

\section{INTRODUCTION}

The Dutch coast is about 350 kilometers in length, from which three quarters consists of sandy beaches and dunes. Large parts of the densely populated areas in the Netherlands are located just behind these dunes, and it would result in dramatic loss of life's and economic damages if these areas are flooded. Because of its important function, it is of great importance that the dunes are maintained, especially in regions where the height and volume of dunes is limited. Besides, the sandy coast represents other important functions in terms of natural values, recreation and attractiveness.

In the last few centuries the dynamics of the Dutch sandy coast decreased due to stabilizing activities under the influence of strict management by Rijkswaterstaat and the water boards. Recently a more dynamic approach to coastal management is adopted (Mulder, 2000). Also, nourishment strategies have changed focus from strengthening the dunes directly by dune and beach nourishments to nourishing the foreshore. This yields a more dynamic system, using the regulatory ecosystem services of aquatic and aeolian transport to redistribute the nourished sand over the system, including the dune area and the lower shoreface.

To optimize long-term coastal management there is a need to have a good understanding of the effectiveness of nourishments. To this end a large effort is made in the development of models that accurately predict coastal evolution. In the past most effort has been in understanding and modeling the wet part of the nearshore coastal area and only limited effort was put in the understanding of aeolian transport processes and associated morphodynamics. Nevertheless it is hypothesized that a morphological analysis of the beach-dune system would improve substantial by including the generic understanding of aeolian transport processes. This understanding of Aeolian processes becomes even more valuable when dealing with a new type of 'mega' nourishment recently constructed in the Netherlands that has a considerable portion of surface area above the water line.

The addition of a (3-dimensional) aeolian transport model could improve the quality of predictions on the effectiveness of nourishments (i.e in feeding the dunes with sand). This paper will therefore focus on the numerical modeling of aeolian transport processes on a sandy beach. An existing model named DUNE (Sauerman et al., 2001) will be used to investigate the influence of morphological shaping by wind. The model has already been applied to describe features and dynamics of typical desert dunes. The paper starts with a description of the DUNE model, followed by a number of test cases typical for a coastal system. Based on the test run results some model extensions are proposed and implemented in the DUNE code. Modifications to the software will be tested in some exploratory simulations.

\footnotetext{
${ }^{1}$ Department of Civil Engineering and Geosciences, Delft University of Technology, Delft, The Netherlands

2 Deltares, Delft, The Netherlands, PO Box 177, Delft, $2600 \mathrm{MH}$, The Netherlands

${ }^{3}$ Department of Water Engineering, UNESCO-IHE, PO Box 3015, 2601 DA Delft, The Netherlands
} 


\section{PROCESS-BASED AEOLIAN MODELING}

\section{Model description}

Sauermann and Hermann aimed to model various dune types and environments with the DUNE model, which resulted in a process-based model approach including a wide range of physical processes (see Figure 1). To solve for the wind shear stress use is made of an analytical solution that holds for smooth hills (Weng et al., 1991). The algorithm is relatively fast w.r.t the averaged Navier-Stokes equations that would simulate a turbulent wind field but would also result in high simulation times. Next, the model includes a saltation model for sand transport from Sauermann et al. (2001), which uses the wind shear stress as input. The advantage of this model is the inclusion of the saturation transients which play an important role in the proper description of increase of sand flux with distance from the water's edge and changes due to arbitrary terrains. From the spatial gradients in computed saltation transport, bed level changes can be computed. The model includes several other modules to incorporate amongst others the possible wake behind a dune, the process of avalanching and the effects of vegetation.

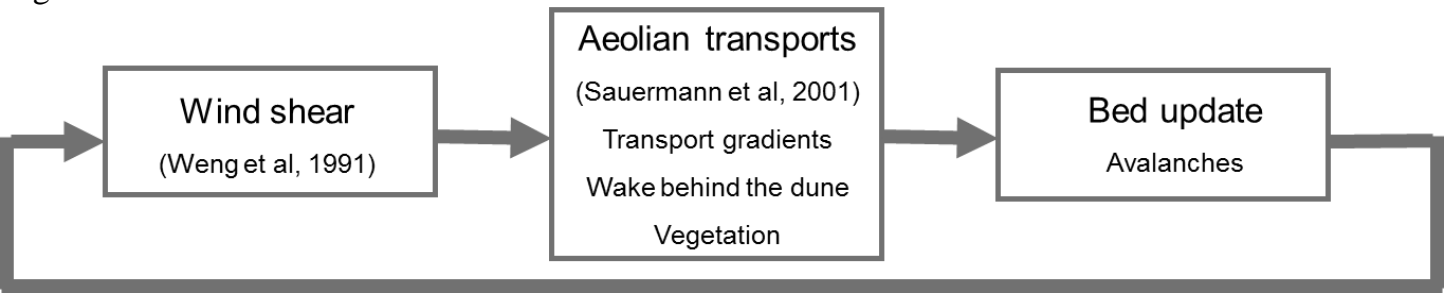

Figure 1. overview of the physical model steps.

The applicability of DUNE to real world desert cases has been extended recently by accounting for bimodal winds (Parteli et al. 2008), which allowed to simulate realistic dune landscapes in deserts (see Figure 2). When the wind direction is not constant but periodically switches, different type of shapes like seif or longitudinal dunes can occur. By varying the range between the dominant wind directions and their duration different dune forms can develop. Also the model was adapted to incorporate a vegetation module, which showed that vegetation growth could transform a barchan dune into a parabolic dune (Duran and Herrmann, 2006).

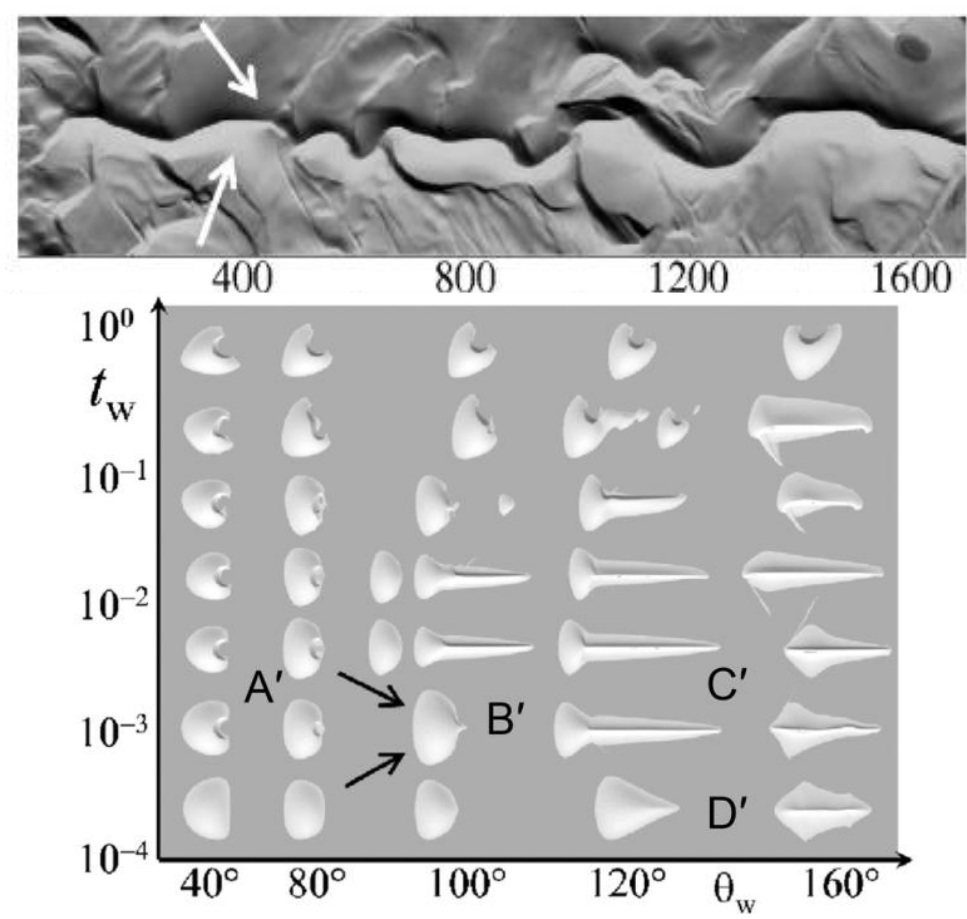

Figure 2. Top view of longitudinal dunes emerged due to a bimodal wind and sand dunes on bedrock with varying angles between directions and characteristic duration (scaled) of these conditions (Parteli et al., 2008). 


\section{Aeolian transport and coastal dune formation}

An understanding of the physical characteristics of sand grains and the manner in which they influence aeolian transport is essential for correct interpretation of wind blown sand flux. The emphasis of the following section will lie on transport across a natural sandy beach. As looking at theoretical phenomena derived from desert sites and wind tunnel tests could underestimate some contributions that are of importance in the coastal zone.

Assumptions valid for a desert with uniform sand conditions and stable governing climate may not automatically translate well to a beach. Therefore, applying a model suitable for modeling desert topographies should be done carefully. According to Gillette et al. (1996) and Bauer et al. (2006) several factors are related to the rate of transport over a cross section of a beach. Primarily, the threshold of grain movement may change over a cross section as a result of grain size, moisture or vegetation. The concept of threshold velocity being dependent on moisture level is confirmed in wind tunnel tests. Literature also suggests the existence of a critical moisture content above which entrainment of sand is difficult and sediment transport is suppressed (e.g. Nickling and DavidsonArnott, 1990), therefore sources of moisture derived from an extern source like precipitation, tides or groundwater can limit transport significantly. Wolfe and Nickling (1993) concluded that vegetation affects sediment transport in several ways, vegetation extracts momentum from the wind field, the part of the surface that is covered with vegetation does not supply the system with sediment and the elements of the vegetation act as an obstacle for the saltation grains. The interaction between vegetation cover, wind speed and supply of sediment from the shore is the controlling factor in the growth of coastal dune fields.

The last factor mentioned by Gillette and Bauer deals with the contribution of the fetch effect. The fetch effect refers to the increase in aeolian transport with downwind distance from the zone of no transport until a certain upper limit in transport (wind driven transport capacity) is reached. The distance over which the transport increases before reaching the wind driven transport capacity is called the critical fetch. In the case of a beach the leading transport edge is the waterline. The maximum available fetch distance is determined by the angle of the incoming wind and the width of the beach. If a beach is sufficiently wide or the wind approach angle is highly oblique, the maximum available fetch can exceed the critical fetch distance. In that case, maximum transport occurs in the area near the upper beach and dunes. This implies that the rate of transport on a beach is not only dependent on typical 'local' factors (i.e. grain size, moisture content and wind speed), but also will depend on fetch geometry (beach width, wind approach angle) (Bauer et al., 2009).

Due to the high complexity and variability it is hard to predict actual rates of transport on beaches. Accurate prediction of Aeolian transport on a beach is only possible if the processes mentioned above are fully understood. Aeolian transport on a beach can depend on a number of additional factors w.r.t. deserts, like moisture content, grain size sorting, details in topography and vegetation cover. In addition, the coastal wind climate with a non-constant wind and varying direction will influence the effective fetch length over a beach and thus transport dynamics.

Finally we remark that inter-tidal beach hydrodynamics and their effect on Aeolian transport are not specifically looked at in this study. However we realize the interaction between 'wet and dry' is an important aspect at coasts where the beach and dunes are always threatened by hydrodynamic forces, but wave and tide action also serve as the input of sediment in the lower beach area.

\section{MODEL EXTENSIONS}

To make the model applicable for the Dutch coastal zone, changes had to be made to several model components. Based on the previous section, several processes can be identified that have to be included in a coastal aeolian transport model. Here we can't include all relevant processes but we will consider three obvious coastal phenomena. The first phenomenon is the variation in beach width due to tidal variations in water level. Secondly, for a coastal engineering case it is also necessary to use actual wind conditions, which cover a much wider range (considering wind speed and wind direction) for the Dutch coast w.r.t. desert conditions. The next step is to explore the capabilities of the model to deal with such a variable wind climate (variable direction and wind speed). Additionally, theoretical cases including the effects of vegetation and sand influx at the boundary are discussed. 


\section{Variable water level}

An important feature of a beach is the presence of a varying water level at the seaward boundary. Varying this level with the tidal phase controls beach width, and thereby potential fetch area for transport. In DUNE, a water level is not included. Instead a non erodible surface can be defined. For this study, the non erodible surface is placed at the height of the theoretical water line by calculating the surface that that should be covered with water and laying the non erodible layer on top of it. As a result only the exposed 'dry' part is affected by the aeolian processes in the model. This method is used to asses the effect of a water level on a beach profile.

\section{Variable wind climate}

For realistic modeling of a beach environment we have to be able to incorporate a non constant wind field that can vary often between a wide range of wind conditions. As demonstrated by Parteli et al. (2008), the model is able to handle bi-modal wind speeds and directions. However, the program is meant for calculations of solitary dunes and not for a alongshore (uniform) dune row (as found along the Dutch coast). Therefore lateral boundary problems arise when oblique wind directions are considered at a coast. Another specific feature of the wind shear stress solver is that for non-zero wind directions not the approach angle of the wind is rotated, but instead the spatial domain (the whole dune system) is rotated. Problems with this approach arise at the edges of the model. Rotating a square grid around its center will lead to parts of the model falling outside the new model domain. When generating the output, the model rotates the surface back but loses information on the old surface area that fell outside the rotated grid. This can be avoided by extending the boundaries of the model domain artificially (Figure 3) before the rotation step leaving the area of interest in the middle of the model.

\section{Extend topography}

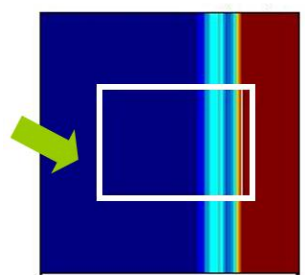

\section{Rotate extended topography,} crop back to comp. domain

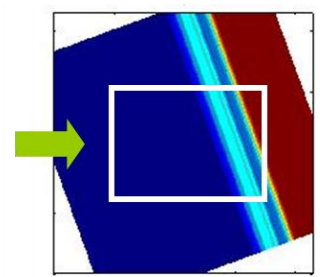

3. Rotate comp. domain to initial orientation

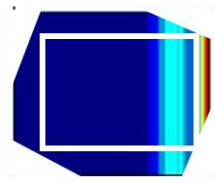

4. Extend domain for next wind direction

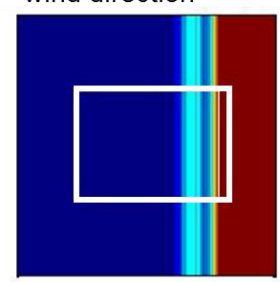

Figure 3. (1) the initial surface (white) is extended. (2) This extended surface is rotated ,this should also include the water level/non erodible surface). The rotated grid is cropped and used for a model run with an associated duration. (3) Model output is rotated back to the original position. (4). Finally, the surface can be extended again for a new wind direction.

\section{EXPLORATORY SIMULATIONS FOR VLUGTENBURG}

The initial test case serves as a learning process for the handling of the model and to spot problems in the model while simulating a beach-dune system. The bathymetry of the initial test case will be a surface profile from a piece of the Holland coast near Vlugtenburg (Figure 4). This beach profile is located at the southwestern part of the Holland coast, about $2 \mathrm{~km}$ northwards of the entrance to the Rotterdam harbor. The beach of Vlugtenburg was extended seawards where an artificial dune row was constructed. An arbitrary beach profile is considered here, that contains interesting features like vegetated dunes and a sandy wet dune valley between the new and old foredune (De Vries et al., 2010).
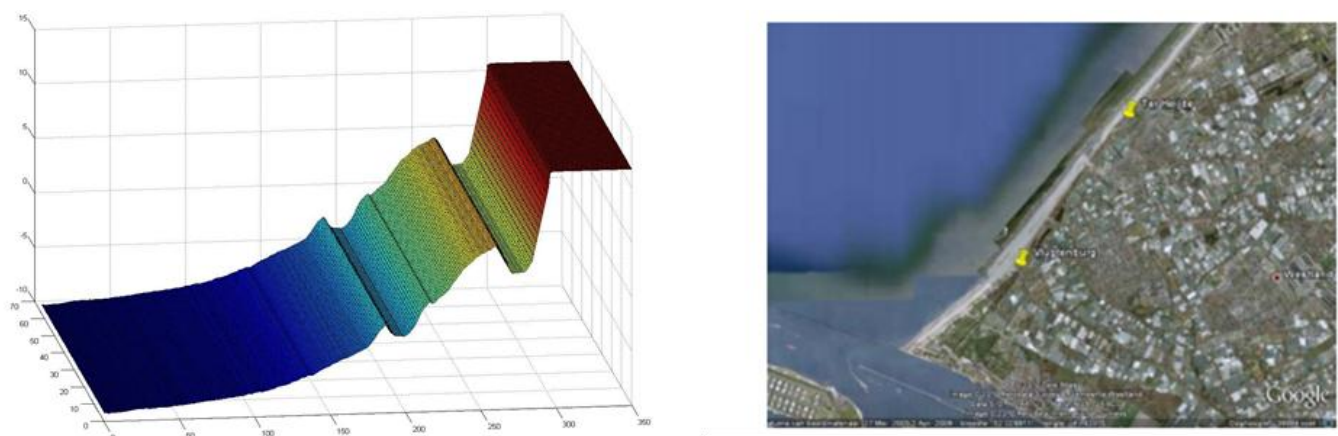

Figure 4. Model schematization and actual project location. 


\section{Effect tide}

Exploring the effect of the tide, the Vlugtenburg profile is subjected to a constant unidirectional onshore wind (during roughly 200 days). The non-erodible surface is implemented, representing the variable water surface. This test assumes no transport of sediment into the model at the upwind boundary. As a base case (no tide), the water level is kept at a constant level (height=0). Variations due to tide are realized by varying the non erodible surface height according to a sine function with frequency (twice a day) and amplitude ( $+/-1$ meter), and by applying historical tide data (source: rijkswaterstaat 2010). The variation of the historical data is more scattered than a perfect sine function.

After running the model to simulate the 200 days, results are shown in figure 5 . The resulting profile shows that in the base case significant erosion can be seen at the water line. The water line retreats over a considerable distance. Using a variable water level the inter-tidal beach evolution is smoothened and the erosion effect is spread out over the area (roughly between -1 and +1 ).

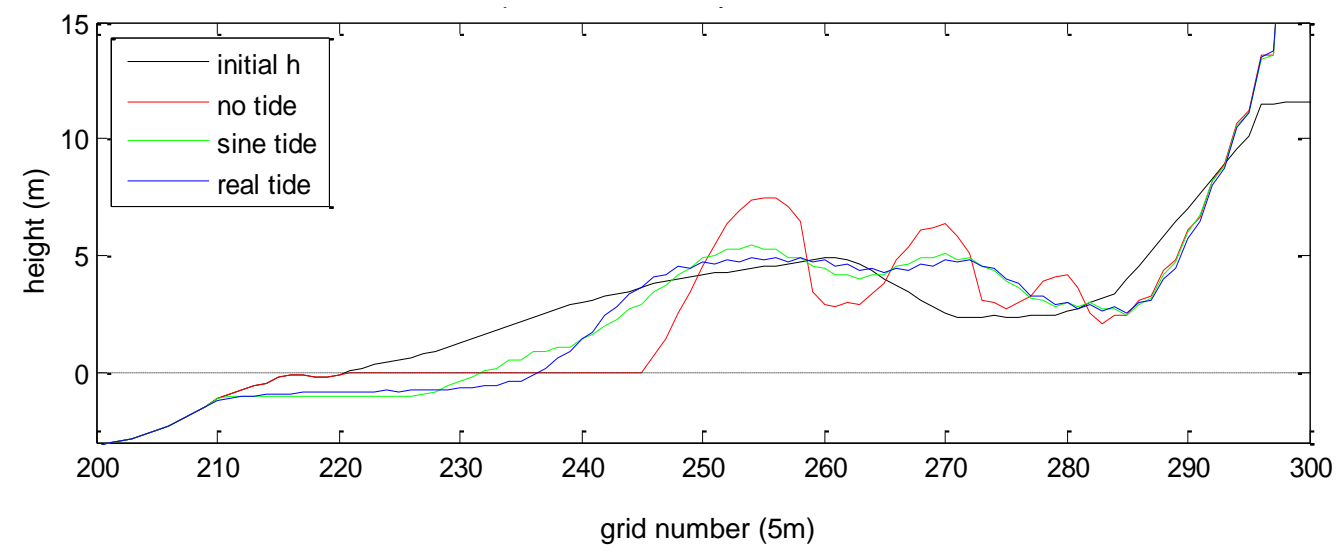

Figure 5. Cross section of the vlugtenburg beach showing the effect of the presence of a water level.

It is concluded that including a varying water level has substantial impact on beach topography. Using a constant water level will result in concentrated erosion at the waterline. The primary cause of this is the lack of sediment input from the upwind direction. The wind has the potential to pick up sediment and when it reaches the intersection between the water level and the beach profile, it erodes the sand at that location. Implementing a fluctuating tidal level spreads this initial pick-up area out. It should be noted only forcing by wind affects the final profile. Hydrodynamic processes in the inter-tidal area could results in a net sediment source to the wet/dry zone preventing the extreme erosion observed in these test simulations. Combining an aeolian sediment transport model with a hydraulic sediment transport model the net effect of aeolian sinks and hydraulic sources to the inter-tidal zone can be assessed in more detail (Den Bieman, 2012).

\section{Effect wind climate}

In this case realistic wind forcing is implemented using actual 2010 wind data at the project site. Wind speed and duration are changed every hour according to data from the Dutch weather service. Because rotating the spatial domain could introduce interpolation errors, a model run is performed with wind and without wind for a period of 5 days (rotating the model 120 times). After the 5 days, the test run without any wind forcing should not diverge from the initial surface profile.

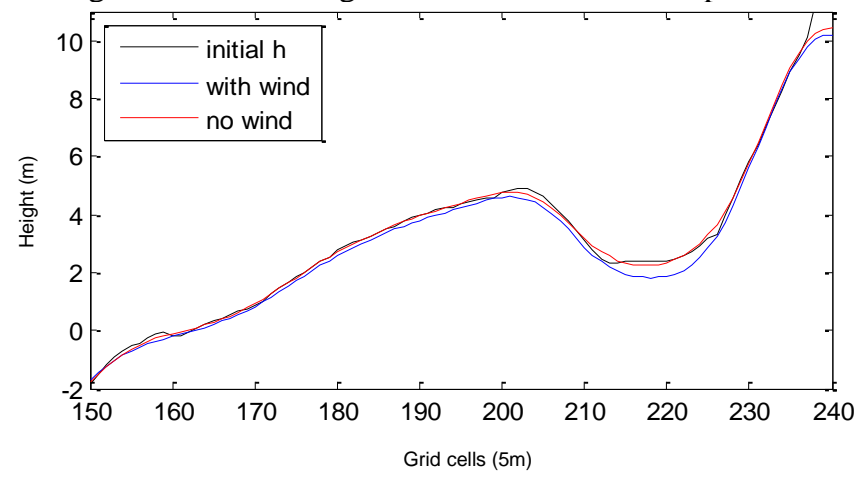

Figure 6. Cross section of the upper beach profile after a period of alternating wind direction. 
Figure 6 shows the results from the Vlugtenburg beach model when forced with realistic wind conditions. In this case it became clear that a calculation with a changing wind direction every hour takes a lot of rotation steps. Simulating a full year will involve 8400 individual wind conditions. The figure shows that information about the surface is lost even in the case with no wind. Performing many of these interpolation steps should be avoided, especially when the resulting errors are of the same order as the surface level changes due to the wind. In order to reduce the number of rotations we recommend that the wind climate should be reduced to a limited number of conditions.

\section{Effect vegetation}

In this case, the effect of vegetation is discussed. A hypothetical initial profile of a beach-dune type situation is used with beach slope $1 / 50$, a beach width of $150 \mathrm{~m}$ and a vegetated dune area (see Figure 7). Again a constant unidirectional onshore wind is imposed to the model. The dune area is initialized with vegetation. The vegetation acts as roughness and absorbs a part of the momentum transferred to the soil by wind. Increasing the spreading of the vegetation should decrease the local effect of sheltering, thus lowering the shear stress. In these tests, the vegetation density will be varied, therefore influencing the degree to what the shear stress is lowered. Sediment influx at the upwind boundary is assumed to be saturated. The influx of sediment at the base of the beach prevents erosion in this area.
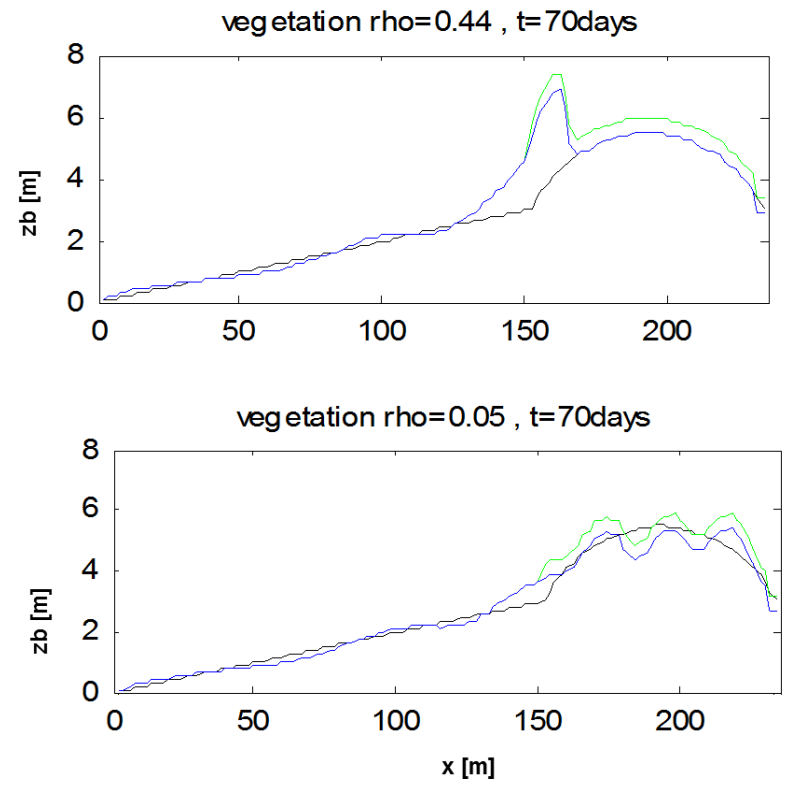

Figure 7. Development of the generic cross section under the influence of a varying vegetation density.

The results in Figure 7 show that vegetation has a substantial influence on the resulting dune landscape. A high density of vegetation captures the sand at the foot of the dune where a high narrow dune develops. For low vegetation density the dune tends to erode and a rolling dune landscape develops. The sand trapping property of the vegetation can qualitatively be captured by the model, more insight is needed in the exact density of typical (Dutch) coastal vegetation density.

\section{Effect sand influx}

In almost all the previous cases, it can be concluded that sand supply onto the beach is a controlling factor for the final profile. Input of the saturated sand flux (dependent on wind speed) at the leading edge of the model should lead to a more stable situation. This model test demonstrates the influence of a boundary influx of sediment on the evolution of the coastal profile (where $q$ in $=1$ corresponds with $100 \%$ saturated influx, see Figure 8). Lowering the influx parameter q should result in an input of sand lower than the saturated value causing erosion in the inter-tidal area. Increasing $q$ should lead to the opposite, local accretion at the entrance of the model. 


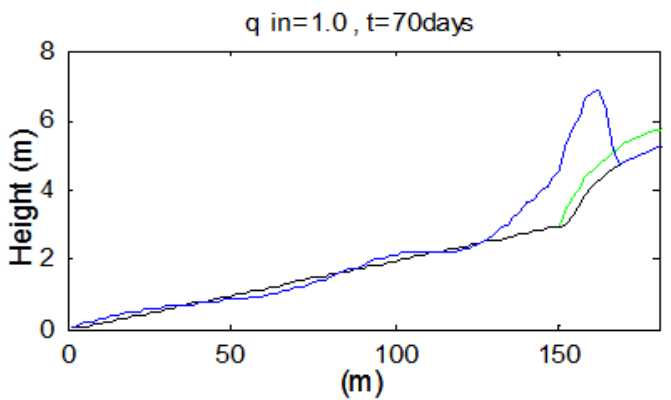

$\mathrm{q}$ in $=1.2, \mathrm{t}=70$ days
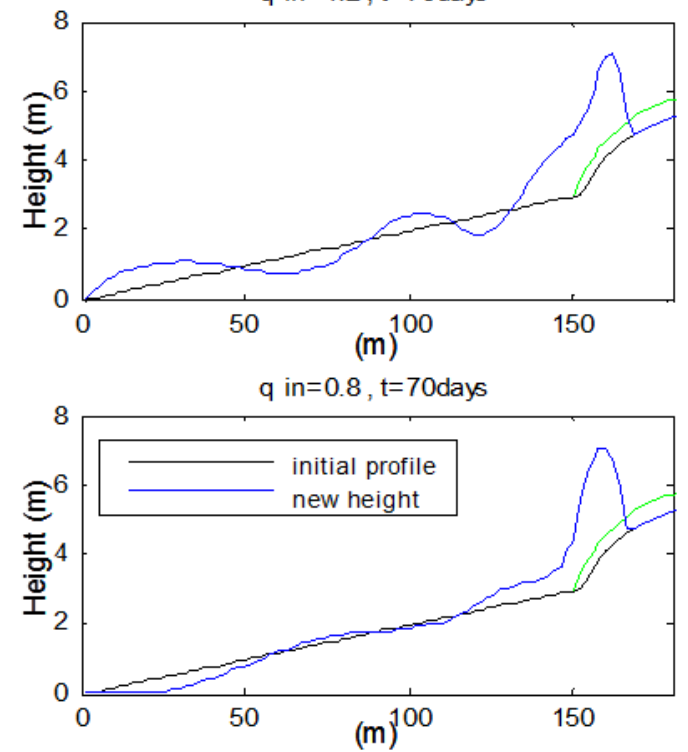

Figure 8. Development of the generic cross section under the influence of a varying influx of sediment.

The effects of erosion and accretion can be seen in the model results shown in Figure 8. When regarding aeolian transport only, we can expect that no supply of sediment will come from the waterland interface. In a realistic coastal situation however, sediment supply to the foredunes will depend on the presence a dry source of swash-deposited sand from the intertidal beach area.

\section{CONCLUSIONS AND FUTURE WORK}

In this study, we have tried to extend an aeolian transport model developed for desert type situations to coastal environments. The model captures the process of aeolian transport and morphologic feedback on the topography, but is limited to aeolian processes only, whereas supply limiting factors such as armoring, sediment moisture are not accounted for at this stage (De Vries et al, submitted).In this paper the model has been assessed in a qualitative way and bed level measurements over time for a morphological active dune area would substantially contribute to the further quantitative validation of the DUNE model.

From conducted model tests it is concluded that including a varying water level has a substantial impact on beach topography. Using a constant water level will result in concentrated erosion at the waterline. Implementing a fluctuating tidal level spreads the erosion area out. We remark that hydrodynamic processes in the dry/wet area can also bring sediment into the inter-tidal preventing the extreme erosion. These processes where not accounted for in this study.

Reduction of wind conditions is recommended to reduce interpolation errors and to speed up simulation time. Simplifying the climate too much will result in average (moderate) conditions, which is not desirable since extreme conditions were found to have significant impact on the yearly transport capacity. A reduced wind climate should still produce the same transport rates as the full dataset. 
Detailed measurements of coastal dune morphology should also contribute to the validation of the vegetation module, The properties of vegetation types like Maram grass should be translated into the vegetation parameters input to the DUNE model. Amongst other properties like plant density, growth speed, maximum height and aerodynamic roughness have to be measured.

The presented model simulations suggest that not only the rate of transport is important for the resulting profile, but also imposed conditions at the seaward boundary or in the driving forces determine the outcome. Several cases show that varying the supply of sediment into the model domain is determining factor for the final beach shape. We remark that sediment input to the lower beach will be difficult to model. A combination of numerical process-based models can provide insight in the relative contribution of hydraulic and aeolian processes shaping a beach, especially at the interface between the sea and the beach. The combined model approach should provide more insight in the interaction between wet and dry parts of the profile, storm events and aeolian dune growth.

\section{ACKNOWLEDGMENTS}

Many thanks to Prof. Hans Herrmann and Dr. Eric Parteli for sharing their code and providing help in understanding it.

\section{REFERENCES}

Bauer, B.O. and R.G.D. Davidson-Arnott, P.A. Hesp, S.L. Namikas, J.W. Ollerhead, I.J. Walker, Aeolian sediment transport on a beach: Surface moisture, wind fetch, and mean transport, 2006

Bauer, B.O. and R.G.D. Davidson-Arnott, P.A. Hesp, S.L. Namikas, J.W. Ollerhead, I.J. Walker. Aeolian sediment transport conditions on a beach: surface moisture and wind fetch effects on mean transport rates. Geomorphology 105 (1-2), 2009

Deltares, Morfologische berekeningen MER zandmotor, 2009

Den Bieman, J.P. Simulating Barrier Island Evolution: Coupling Process-Based Models, MSc Thesis, Delft University of Technology, 2012

De Vries, S and M. De Schipper, M. Stive, R. Ranasinghe, sediment exchange between the sub-aqueous and sub-aerial coastal zones. coastal engineering, 2010

De Vries, S., in prep. Sediment transport gradients on the beach, the role of wind speed, sediment supply and fetch effects. Aeolian Research.

Gillette, D.A., and Herbert, G., Stockton, P.H. Owen, P.R.,. Causes of the fetch effect in wind erosion. Earth Surface Processes and Landforms, 1996

Herrmann, H.J., O. Durán, E.J.R. Parteli,V. Schatz, Vegetation and Induration as Sand Dunes Stabilizators, 2006

Kroy, K and G. Sauermann, H.J. Herrmann, A minimal model for sand dunes, Phys. Rev. Lett. 88, 054301, 2002

Mulder, J.P.M., 2000. Advies voor Dynamisch Handhaven in de 21e eeuw. RIKZ, 2000

Muller, M.C. 2011, Process-based Modeling of Coastal Dune Development, MSC. Thesis, Delft University of Technology.

Nickling, W. G. and Davidson-Arnott, R. G. D. 1990. Aeolian sediment transport on beaches and coastal sand dunes. In, Davidson-Arnott, R.G.D. (editor), Proceedings of the Symposium on Coastal Sand Dunes. National Research Council of Canada, 1-35.

Parteli, E.J. R. and O. Durán, H. Tsoar, V. Schwämmle, H.J. Hermann, Dune formation under bimodal winds ,2008

Sauermann, G and K. Kroy, H. J. Herrmann. A continuum saltation model for sand dunes. Phys. Rev. , 2001.

Weng, W. S. et al. 1991, Air flow and sand transport over sand-dunes, Acta Mech. Suppl. $2,1$.

Wolfe S.A. and W.G. Nickling. 1993. The protective role of sparse vegetation in wind erosion. Progress in Physical Geography 17: 50-68. 